\title{
Comparing three different methods to model scenarios of future glacier change in the Swiss Alps
}

\author{
Andreas LINSBAUER, ${ }^{1}$ Frank PAUL, ${ }^{1}$ Horst MACHGUTH, ${ }^{1,2}$ Wilfried HAEBERLI ${ }^{1}$ \\ ${ }^{1}$ Department of Geography, University of Zürich, Zürich, Switzerland \\ E-mail: andreas.linsbauer@geo.uzh.ch \\ ${ }^{2}$ Geological Survey of Denmark and Greenland, Copenhagen, Denmark
}

\begin{abstract}
Ongoing atmospheric warming causes rapid shrinking of glaciers in the European Alps, with a high chance of their near-complete disappearance by the end of the 21st century. Here we present a comparison of three independent approaches to model the possible evolution of the glaciers in the Swiss Alps over the 21st century. The models have different levels of complexity, work at a regional scale and are forced with three scenarios of temperature increase (low, moderate, high). The moderate climate scenario gives an increase in air temperature of $\sim 2^{\circ} \mathrm{C}$ and $\sim 4^{\circ} \mathrm{C}$ for the two scenario periods 2021-50 and 2070-99, respectively, resulting in an area loss of $60-80 \%$ by 2100 . In reality, the shrinkage could be even faster, as the observed mean annual thickness loss is already stronger than the modelled one. The three approaches lead to rather similar results with respect to the overall long-term evolution. The choice of climate scenarios produces the largest spread $(\sim 40 \%)$ in the final area loss, while the uncertainty in present-day ice-thickness estimation causes about half this spread.
\end{abstract}

\section{INTRODUCTION}

Ongoing glacier shrinkage in the European Alps is of increasing interest because of the expected changes in the hydrologic regime of major river catchments (e.g. Mauser and Bach, 2009; Huss, 2011) and its influence on hydropower production (e.g. Schaefli and others, 2007; Terrier and others, 2011; Farinotti and others, 2012), tourism (Fischer and others, 2011) and natural hazards (e.g. Moore and others, 2009; Frey and others, 2010; Haeberli and others, 2010; Künzler and others, 2010). Scenarios of future climate change with further increasing temperatures (Solomon and others, 2007) involve continued, if not accelerated, glacier shrinkage, and even the possibility of complete loss of glaciers in entire mountain ranges (e.g. Zemp and others, 2006). Several methods, based on different basic concepts, complexity and application scales, have been developed to determine future glacier evolution (i.e. change in glacier area and/or volume) along with the related changes in runoff. Such glacier models can either be regionally calibrated empirical/statistical models or process-oriented models, which are more physically based (Hoelzle and others, 2005).

For modelling glacier evolution at the scale of entire mountain ranges, a variety of simple techniques and approaches (requiring only few input data) have been applied in the past. Examples are a shift of the equilibrium-line altitude (ELA), according to given changes in temperature and/or precipitation and the related change of the accumulation area (e.g. Lie and others, 2003; Zemp and others, 2006; Condom and others, 2007; Paul and others, 2007), the application of various spatio-temporal extrapolation techniques (Huss, 2012) or the parameterization scheme for glacier inventory data introduced by Haeberli and Hoelzle (1995). Using even more simplified methods, future glacier changes are also modelled at a global scale, for example to assess the future contribution of glaciers to sea-level rise, mostly as a combination of analogy concepts and multivariate analysis with strongly abstracted glaciers (e.g. Raper and Braithwaite, 2005; Bahr and others, 2009; Marzeion and others, 2012). Radić and Hock (2011) and
Raper and others (2000) considered the change in a standardized area/elevation distribution (hypsometry) to account for the adjustment of glacier area to future climate conditions. A more direct way to determine future glacier evolution is the calculation of glacier volume loss based on observed overall changes in glacier thickness, as derived from geodetic measurements (e.g. differencing of two digital elevation models (DEMs)) over a longer time period (e.g. Huss and others, 2010a). Based on these observations, simple parameterizations of thickness evolution can be derived and, in combination with calculated ice-thickness distributions (e.g. Farinotti and others, 2009; Linsbauer and others, 2012) and mass balances (e.g. Giesen and Oerlemans, 2012), be applied to large glacier samples (e.g. Huss, 2011; Salzmann and others, 2012).

A variety of more complex approaches exist to model future glacier evolution, based on mass-balance modelling and glacier flow (e.g. Le Meur and others, 2007; Jouvet and others, 2009, 2011). These models are computationally expensive and only applicable to individual well-studied glaciers, where sufficient data (also for calibration and validation) exist.

Ultimately, the glacier-evolution models described above must be linked to a climate scenario, and changes should be time-dependent. Although models that are based on massbalance calculations can be directly linked to climate model output (e.g. Machguth and others, 2009), the modelled mass change is not identical to thickness change, as the geometric adjustment of a glacier (change in area or length) to a massbalance forcing will only occur after a delay. Using a (surface) mass-balance model to determine future glacier evolution has thus to implement a parameterization of mass transport. This can be obtained by a comparison of the modelled cumulative mass budget and the observed overall volume loss over the same period (Huss and others, 2010a). For the simpler approaches (e.g. shift in the ELA) the link to a certain climate scenario can be established, based on atmospheric lapse rates or known relations between ELA change and changes in temperature, precipitation and the energy balance 


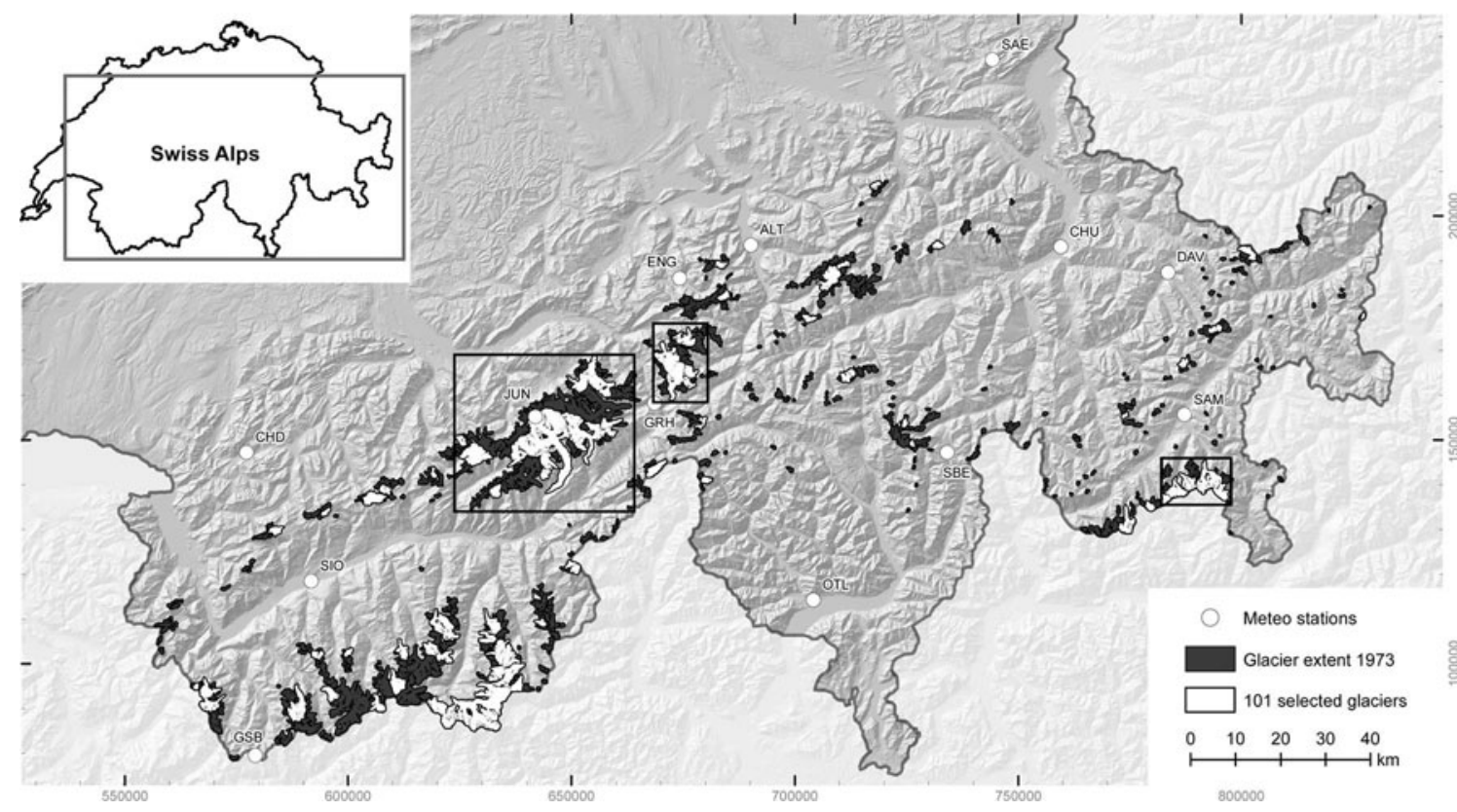

Fig. 1. The model domain 'Swiss Alps' with the subsample of 101 selected glaciers marked. The white points denote the locations of the MeteoSwiss weather stations with homogenized annual mean temperature data for the period 1980-2009. ALT: Altdorf (438 m a.s.I.), CHD: Chateau-d'Oex (985 m a.s.l.), CHU: Chur (556 m a.s.l.), DAV: Davos (1594 m a.s.l.), ENG: Engelberg (1035 m a.s.l.), GRH: Grimsel Hospiz (1980 m a.s.I.), GSB: Col du Grand St Bernhard (2472 ma.s.I.), JUN: Jungfraujoch (3580 m a.s.l.), OTL: Locarno/Monti (366 m a.s.I.), SAE: Säntis (2502 m a.s.I.), SAM: Samedan (1708 m a.s.I.), SBE: S. Bernardino (1638 m a.s.l.) and SIO: Sion (482 m a.s.I.). Black rectangles show the extent for Figures 4 and 7.

(e.g. Kuhn, 1981). However, the involved time dependence of the geometric adjustment has to be introduced artificially, for example based on estimated response times for larger glacier samples (e.g. Haeberli and Hoelzle, 1995).

Although the various existing approaches have structurally different designs and use different climate forcings, they tend to provide similar results. A model intercomparison can help to tease out model-specific problems and hence sources of uncertainty for simulations and predictions. Thereby, the boundary conditions for the compared approaches are usually held constant and the models compared are conceptually rather similar. Models that use conceptually different approaches have not, so far, been analysed together. Here we compare three methods of variable complexity applicable to large glacier populations and focus on the glaciers of the Swiss Alps.

One model (M1; Section 3.1) provides future glacier area only, and is based on an adjustment of the hypsometric area distribution following an upward shift of the ELA (Paul and others, 2007) according to three scenarios of climate change.

A second approach (M2; Section 3.2) uses a modelled ice-thickness distribution in combination with observed geodetic volume changes for an extrapolation of the elevation-dependent thickness change and related area evolution into the future, assuming a constant rate of icethickness loss as a reaction to temperature increasing by $1{ }^{\circ} \mathrm{C}$ in time-steps of 20,25 and 30 years.

A third method (M3; Section 3.3) uses a distributed massbalance model that is directly coupled to three ensembles of downscaled, de-biased, gridded and transient regional climate model (RCM) simulations (Machguth and others, 2009, 2012; Salzmann and others, 2012), in combination with a hypsometric change in glacier geometry using the parameterization by Huss and others (2010a).

Besides comparing the modelled glacier extents, hypsometric distributions and relative area loss for $M 1, M 2$ and M3, we also analysed the uncertainties introduced by model simplifications, the ice-thickness estimations and the climate change scenarios. Because future glacier extents or runoff from glacierized catchments cannot be validated, a validation can only be performed over the recent past. We thus compared the modelled area and/or volume changes over the 1985-2000 period with the observed ones, being well aware that none of the three models are designed to give reliable results over such a short timescale.

\section{STUDY REGION AND INPUT ATA}

The study region of the Swiss Alps comprises an area of $\sim 25000 \mathrm{~km}^{2}$ including a glacierized area of $\sim 1300 \mathrm{~km}^{2}$ in 1973 (Müller and others, 1976) (Fig. 1). The DEM covering the study site was produced by the Swiss Federal Office of Topography (swisstopo), has a cell size of $25 \mathrm{~m}$ (termed DEM25 in the following) and approximately represents the glacier surfaces around 1985 (Rickenbacher, 1998; swisstopo, 2005). The accuracy of the DEM25 is reported to be $2.5-7.5 \mathrm{~m}$ in the horizontal direction and $<10 \mathrm{~m}$ in the vertical direction (swisstopo, 2005). The digital glacier outlines are based on the digitized Swiss Glacier Inventory from 1973 (SGl1973) by Müller and others (1976), in the revised version by Maisch and others (2000) which includes 2365 glacier and glacierets $>0.01 \mathrm{~km}^{2}$. These glacier polygons fit well to the glacier extent in the DEM25, as only small overall area changes took place for most glaciers in the Alps between 1973 and 1985 (Paul and others, 2004). 


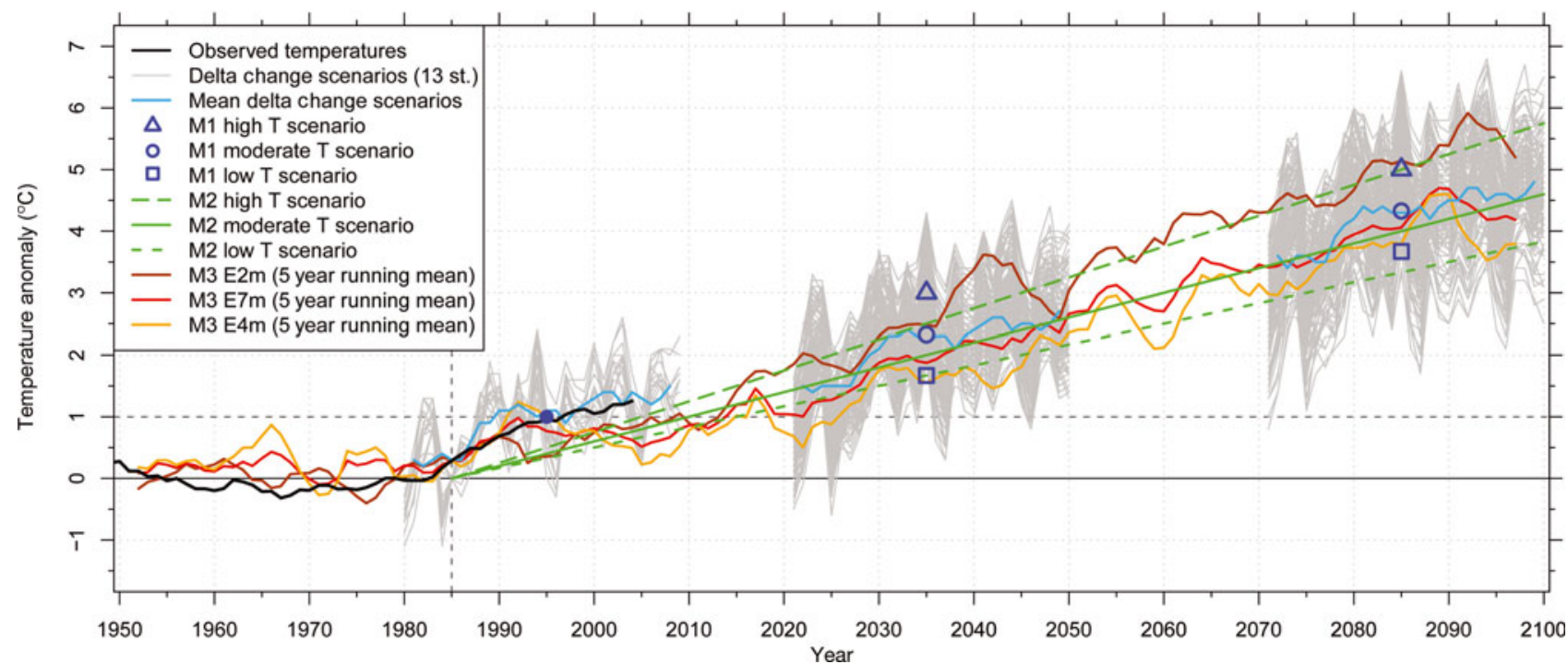

Fig. 2. Anomaly of $2 \mathrm{~m}$ air temperature of the observed temperatures and climate scenarios used, all normalized to the reference period from 1961-90 for Switzerland (after Rebetez and Reinhard, 2008). As a reference, the annual temperature anomalies (Rebetez and Reinhard, 2008) from 12 homogenized temperature series for 12 stations in Switzerland (Begert and others, 2005) are displayed in black. The grey lines show observed temperatures from 13 MeteoSwiss weather stations (Fig. 1) for the control period 1980-2009 and their projections to the two scenario periods 2021-50 and 2070-99 according to the delta change values and ten different model chains from Bosshard and others (2011). In light blue the 5 year running mean for the measurements and the projections for the 13 weather stations are shown. The blue point is the starting point for all three M1 scenarios, and the triangle, circle and square mark the low-, moderate- and high-temperature scenarios for M1. The lines of the linear extrapolated temperature trends, as used for M2, are shown in green. The 5 year running mean for three scenario ensembles (E2m, E7m and E4m) used for M3 are shown in in orange, red and brown.

While the first two models (M1 and M2) were applied to all glaciers in the Swiss Alps, M3 was restricted to a sample of 101 selected glaciers, as explained in Section 3.3, representing $\sim 50 \%$ of the total glacierized area and $\sim 75 \%$ of the ice volume in Switzerland.

The ice-thickness distribution for all Swiss glaciers is calculated with the GlabTop model (Linsbauer and others, 2012; Paul and Linsbauer, 2012) using the DEM25 and the glacier outlines from the SGI1973 as inputs. GlabTop spatially extrapolates locally (50 $\mathrm{m}$ elevation bins) estimated glacier thickness values that are derived from averaged values of surface slope and a mean basal shear stress per glacier (assuming perfect plasticity; see Paterson, 1994). The basal shear stress was empirically derived from the glacier elevation range, which can be seen as a proxy for mass turnover (Haeberli and Hoelzle, 1995), and has an upperbound value of $150 \mathrm{kPa}$ for glaciers exceeding an elevation range of $1.6 \mathrm{~km}$ ( $\mathrm{Li}$ and others, 2012). The obtained model results have an uncertainty range of about $\pm 30 \%$, as shown by a comparison with independent radar profiles and an uncertainty analysis (Linsbauer and others, 2012).

The presence of glaciers, their number and characteristics are mainly linked to the elevation of their headwater catchment, which determines the seasonality of the runoff regime (mostly pluvio-nival or glacio-nival). Most Swiss glaciers (exceptions are found in the Val Bregaglia and the Val Fenga) are drained by seven major river catchments with gauging stations in the lowlands. In combination with the outlines of these major river catchments, the grid from the DEM differencing (Shuttle Radar Topography Mission DEM (SRTM3) - DEM25) by Paul and Haeberli (2008) was used to obtain catchment-specific elevation changes over the period 1985-99, based on zone statistics (with each major river catchment as a zone). Apart from a few regions with data voids over glaciers, this dataset covers nearly all glaciers in the Swiss Alps. The mean change of the DEM differencing $(-11 \mathrm{~m}$ w.e.) is in good agreement with the mean cumulative mass budget of nine Alpine glaciers with measured mass balances $(-10.8 \mathrm{~m}$ w.e.).

Both the reported temperature data from Rebetez and Reinhard (2008) and the measured temperatures from 13 selected weather stations (Fig. 2) run by the Swiss Federal Office of Meteorology and Climatology (MeteoSwiss) show a distinct temperature increase of $\sim 1^{\circ} \mathrm{C}$ between 1980 and 1995. From the 1990s until the present the temperatures further increased (by $\sim 0.5^{\circ} \mathrm{C}$ ), but at a lower rate (Fig. 2).

The three climate scenarios applied here are derived from ten climate model chains (combination of a general circulation model (GCM) and an RCM) using an A1B emission scenario (Solomon and others, 2007) at a $25 \mathrm{~km}$ horizontal resolution from the EU-ENSEMBLES program (Van der Linden and Mitchell, 2009). Values for temperature and precipitation for several MeteoSwiss weather stations were downscaled for the scenario periods 2021-50 and 2070-99 (relative to the control period 1980-2009) by Bosshard and others (2011) using a delta change approach. From the resulting temperature increase at 13 weather stations we derived low, moderate and high scenarios, that cover the range of model chain variability. The moderate scenario gives an increase in air temperature of $2^{\circ} \mathrm{C}$ and $4^{\circ} \mathrm{C}$ for the two scenario periods centred around 2035 and 2085, respectively.

Glacier development until the first scenario period in model $\mathrm{M} 1$ is based on the reaction to the $1^{\circ} \mathrm{C}$ temperature increase that took place in the 1980s. After that, glaciers react to the three scenarios of temperature increase derived for the first scenario period. The three scenarios for model M2 follow three linear trend extrapolations, assuming that the abovementioned temperature increase of $1^{\circ} \mathrm{C}$ is repeated every 


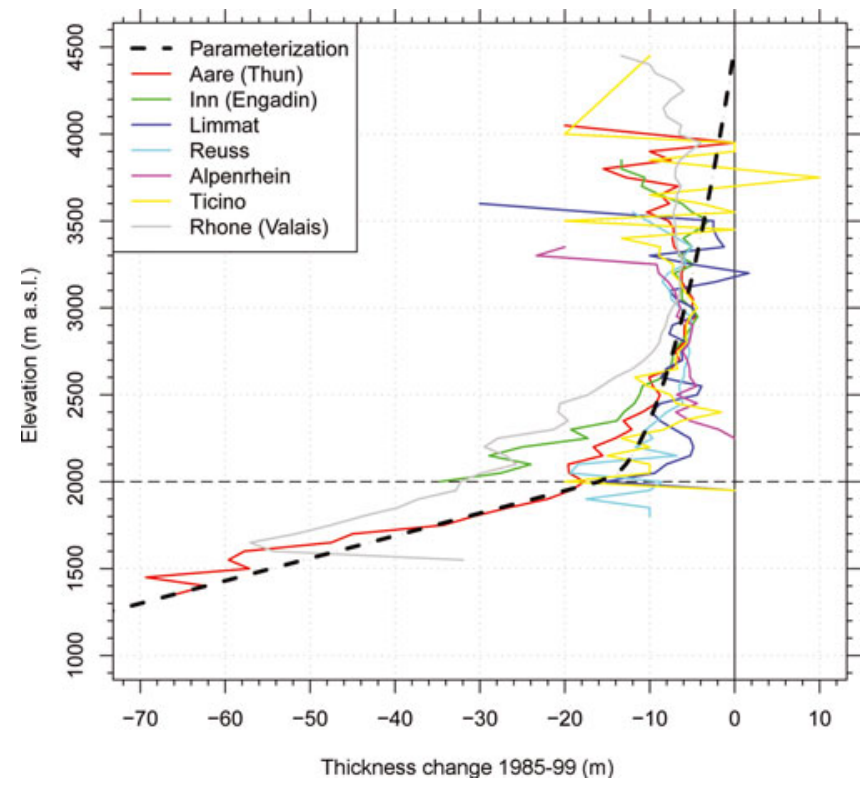

Fig. 3. Thickness changes from 1985 to 1999 (Paul and Haeberli, 2008) for seven major river catchments, together with an empirical elevation-dependent function to parameterize the thickness loss for all Swiss glaciers in model M2 (Eqn (1)).

20, 25 or 30 years. The 25 year repeat period (i.e. the moderate scenario) also gives a $2^{\circ} \mathrm{C}$ and $4^{\circ} \mathrm{C}$ temperature increase by 2035 and 2085 (Fig. 2). The distributed massbalance model applied in M3 is directly forced with three ensemble means of the A1B scenario using RCM simulations from ENSEMBLES, assuming ensemble means are the most plausible scenario guess (e.g. Guo and others, 2007). Ensemble E7m consists of seven different RCM realizations (driven by ECHAM5-r3, HadCM3Q0 and the ARPEGE GCMs), E4m consists of four RCMs all driven with ECHAM5-r3 and $E 2 \mathrm{~m}$ is the ensemble of the two HadCM3Q0-driven ensembles (Salzmann and others, 2012). Monthly resolution RCM grids were chosen because the daily resolution grids showed unrealistic variability in daily precipitation.

The climate model input datasets are thus different by source, but not by value (Fig. 2). The moderate scenarios from $\mathrm{M} 1$ and $\mathrm{M} 2$, as well as E7m from M3 (the moderate scenario used in this model), all project a $2^{\circ} \mathrm{C}$ temperature increase for the two scenario periods centred around 2035 and 2085.

\section{METHODS}

For all three models, the initial glacier extent is given by the glacier outlines from 1973 (SGl1973; Maisch and others, 2000) and the swisstopo DEM25 with $25 \mathrm{~m}$ resolution, referring to the glacier surfaces at around 1985. The starting point 1973/1985 was chosen as most glaciers were close to a dynamic steady state then. The required ice-thickness distribution for models M2 and M3 is taken from Linsbauer and others (2012).

\subsection{ELA-shift model (M1)}

The ELA-shift model is described by Paul and others (2007) and thus only briefly outlined here. The model is based on the fact that with rising temperatures the ELA of glaciers is shifted to higher elevations (here by $150 \mathrm{~m} \mathrm{~K}^{-1}$; Kuhn, 1981), resulting in smaller accumulation areas and, after some time, smaller glacier extents. Using a balanced budget accumulation-area ratio, $\mathrm{AAR}_{0}$, of $60 \%$ (WGMS, 2011), new total glacier sizes can be calculated and adjusted by removing the lowermost parts of a glacier. This model only provides information on how large glaciers will be after full adjustment, without saying when this will happen. To link the glacier adjustment to a timescale considering that response times vary from $\sim 5$ to maybe 100 years or more, the same mean response time of 50 years (Haeberli and Hoelzle, 1995) is assumed for all glaciers. This matches the years 2035 and 2085, the centred scenario periods when starting from 1985. In order to have model results in 5 year time-steps, the total area change over the 50 year response time was divided into ten single steps.

There are several restrictions to the validity of the model, due to the simplicity of the approach. The model calculates new glacier extents for given ELA shifts and a hypothetical new steady state. However, equilibrium is not reached in reality, as the climate is in constant change and glaciers continuously adjust their extents to new climatic conditions, depending on their specific geometry and response times. With a constant 50 year response time for all glaciers, the speed of area change is overestimated for the largest and underestimated for small glaciers. As this approach works in two dimensions only, the introduced response time only serves for adjustment of the area (thickness changes are not considered) to make the method time-dependent. Moreover, the balanced budget, $\mathrm{AAR}_{0}$, might vary between $50 \%$ and $70 \%$ for individual glaciers (Machguth and others, 2012), while here it is assumed to be constant and the same for all glaciers.

M1 is coupled with climate in a retrospective manner. The 50 year response time period for all glaciers starts in 1985 (running to 2035 and 2085 in the model). In the first period all glaciers react to the $1^{\circ} \mathrm{C}$ temperature increase of the mid1980s (Fig. 2 and Rebetez and Reinhard, 2008) that resulted in a $150 \mathrm{~m}$ increase of the ELA. In the second period, the glaciers react to the warming of the first 50 years according to three different temperature scenarios. These scenarios are derived from the means of the delta change values from ten RCM models yielding an increase in ELA of $+100 \mathrm{~m}$ (lowtemperature scenario), $+200 \mathrm{~m}$ (moderate) and $+300 \mathrm{~m}$ (high). Thus it is a step-change and retrospective response model, i.e. reacting to a forcing that has taken place in the past. The 5 year time-steps are only used to generate a smooth transition between the two steady-state extents.

\subsection{Thickness change parameterization (M2)}

Since the beginning of the 1980s, increasingly negative glacier mass balances have been observed in the Alps (WGMS, 2011). The related thickness change for the period 1985-99 was calculated for all Swiss glaciers from DEM differencing (Paul and Haeberli, 2008), revealing strong thickness losses for low-lying and flat glacier tongues. This illustrates that the adaptation of the glacier extent to a rapidly changing climate can be dominated by thickness loss (downwasting) rather than area change (Huss and others, 2008, 2010a). Plotting thickness loss vs altitude for the major river catchments reveals a rather similar and increasing thickness loss towards lower elevations for all regions (Fig. 3). To parameterize this for the entire study region, we used (similarly to Huss and others, 2010a) an empirically derived elevation-dependent function as an average for catchment-related mean values composed of a 
lower $(<2000 \mathrm{~m})$ linear decline and an upper $(>2000 \mathrm{~m})$ quadratic decrease:

$$
\frac{\mathrm{d} h}{\mathrm{~d} t}= \begin{cases}-70+\left(\mathrm{DEM}_{i}-1300\right) \cdot \frac{54}{700} & \text { if } \mathrm{DEM}_{i} \leq 2000 \\ -16+\left(\mathrm{DEM}_{i}-2000\right)^{1 / 2} \cdot \frac{25}{8} & \text { if } \mathrm{DEM}_{i}>2000\end{cases}
$$

with $\mathrm{d} h / \mathrm{d} t$ the rate of thickness change $\left(\mathrm{ma}^{-1}\right)$ within the specified time period and $\mathrm{DEM}_{i}$ the elevation (ma.s.l.) of each gridcell. Of course, the assumption that all glaciers are subject to the same elevation-dependent thinning rates is not correct (e.g. delay due to debris cover or different shading conditions) and the resulting area changes can be strongly over- or underestimated for individual glaciers. Above $3000 \mathrm{~m}$ the approximation of the parameterization differs from the extracted thickness loss rates in Figure 3, but values in this elevation range are influenced by artefacts in the SRTM3 DEM. The decrease to zero at the highest elevations is implemented to keep small, steep and thus thin glaciers at high elevations from disappearing too fast. The function used is an empirical one, rather than derived by a regression, to better accommodate the DEM uncertainties and model needs mentioned above. In this regard it has to be stressed that the modelled area changes are assumed to be realistic only at the regional scale (e.g. for major river catchments).

M2 is coupled with climate by (1) relating the observed thickness change from 1985 to 1999 to the observed temperature increase of $1{ }^{\circ} \mathrm{C}$ mentioned above and (2) assuming that the glacier surface will adjust to this forcing over a 20, 25 or 30 year time period (Fig. 2). This trend is then assumed to continue into the future (linear extrapolation), resulting in a $1{ }^{\circ} \mathrm{C}$ temperature increase every 20, 25 and 30 years. Glacier area is removed once the cumulative icethickness loss exceeds the initial ice thickness. Each time the thickness change increment is subtracted from the initial DEM, the glacier surface gradually shifts to lower elevations, where the rate of thickness loss is higher.

\subsection{Glacier mass-balance simulation and retreat modelling for 101 glaciers (M3)}

Glacier mass balance is calculated using a distributed massbalance model (Machguth and others, 2009). This is a simplified energy-balance model, which runs at daily timesteps and uses gridded RCM data of $2 \mathrm{~m}$ air temperature, $T$, precipitation, $P$, and total cloudiness, $n$, for input. Because of spurious values in the daily RCM fields, the data applied here are at monthly resolution. Daily values are generated from linear interpolation, and precipitation falls every fifth day (Salzmann and others, 2012). Cumulative mass balance, $b_{\mathrm{c}}$, on day $t+1$ is calculated for every time-step and over each gridcell of the DEM, according to Oerlemans (2001):

$$
b_{\mathrm{c}}(t+1)=b_{\mathrm{c}}(t)+ \begin{cases}\Delta t \cdot\left(-Q_{\mathrm{m}}\right) / I_{\mathrm{m}}+P_{\text {solid }} & \text { if } Q_{\mathrm{m}}>0 \\ P_{\text {solid }} & \text { if } Q_{\mathrm{m}} \leq 0\end{cases}
$$

where $t$ is the discrete time variable, $\Delta t$ is the time-step, $I_{\mathrm{m}}$ is the latent heat of fusion of ice $\left(334 \mathrm{~kJ} \mathrm{~kg}^{-1}\right)$ and $P_{\text {solid }}$ is solid precipitation (m w.e.). The energy available for melt, $Q_{m}$, is calculated as

$$
Q_{\mathrm{m}}=(1-\alpha) S_{\text {in }}+C_{0}+C_{1} T
$$

where $\alpha$ is the surface albedo (three constant albedo values are applied: snow $=0.72$, firn $=0.45$ and ice $=0.27), S_{\text {in }}$ is the incoming shortwave radiation at the surface, calculated according to Greuell and others (1997) from $n$ and clear-sky global radiation computed at DEM resolution and taking all effects of exposition and shading into account, $T$ is in ${ }^{\circ} \mathrm{C}$, and $C_{0}+C_{1} T$ is the sum of the longwave radiation balance and the turbulent exchange (Oerlemans, 2001). $C_{1}$ is set to $12 \mathrm{~W} \mathrm{~m}^{-2} \mathrm{~K}^{-1}$ and $C_{0}$ is tuned to $-45 \mathrm{~W} \mathrm{~m}^{-2}$ (Machguth and others, 2009). Accumulation is equal to $P_{\text {solid, the redis- }}$ tribution of snow is not taken into account and a threshold range of $1-2^{\circ} \mathrm{C}$ is used to distinguish between snowfall and rain. Any meltwater is considered as runoff, i.e. refreezing and internal storage of meltwater is neglected.

Glacier retreat is simulated based on the modelled mass balances and the so-called $\Delta h$ glacier-retreat approach, following Huss and others (2010a). The latter parameterize glacier surface elevation change by distributing glacier mass loss or mass gain over the entire glacier surface, according to altitude-dependent functions of observed changes in glacier thickness. Here we use the glacier-size-dependent $\Delta h$ functions as proposed for the Swiss Alps (Huss and others, 2010a, fig. 3b therein). Glacier geometry is updated annually, based on calculated surface elevation changes. Glacier surface mass balance is calculated on the updated topography and thus considers the mass-balance/altitude feedback, i.e. a reduction in glacier thickness results in a lower elevation of the glacier surface and consequently a more negative mass balance (e.g. Raymond and others, 2005). Glacierized gridcells become ice-free when their elevation falls below the elevation of the glacier bed.

Simplifications in the mass-balance model used (e.g. debris cover is not considered) limit the number of glaciers where reasonable mass balances can be calculated. Therefore, 101 glaciers are selected from the SGl1973, based on the following criteria: (1) no or little debris cover; (2) no or little influence of avalanches; (3) mass loss restricted to melting (the applied mass-balance model does not consider any processes like calving into lakes or over rock faces); and (4) sufficient size $\left(>1 \mathrm{~km}^{2}\right)$, as small glaciers usually show accumulation patterns of a very local nature with strong influence from wind-drift and avalanching.

M3 is coupled to climate using gridded RCM fields for model input, rather than projected temperature change at weather station locations (cf. models M1 and M2). The direct use of the RCM fields involves the two steps of (1) downscaling the gridded $25 \mathrm{~km}$ resolution fields to the $100 \mathrm{~m}$ resolution of the mass-balance model, and (2) de-biasing the downscaled RCM fields. These two steps are implemented in the mass-balance modelling set-up and directly applied to each RCM grid while the model is running. The downscaling of $T$ and $P$ is based on interpolation of the RCM values with the subsequent application of simple subgrid parameterizations, while $S_{\text {in }}$ is computed from high-resolution clearsky global radiation and attenuation from clouds derived from interpolated total cloudiness, $n$ (see Machguth and others, 2012, for full details).

The de-biasing of the RCM fields is done for each variable, according to the method described by Machguth and others (2012), where biases in RCM values of $T$ and $n$ are established from comparison with observations at 14 highmountain weather stations in the Swiss Alps and spatial distribution of RCM precipitation is scaled to match the precipitation pattern of the Schwarb and others (2001) precipitation map. However, the accuracy of the downscaled and de-biased fields is limited, as knowledge of real meteorological conditions at the glacier sites is imperfect. In particular, the large uncertainties in observed highmountain precipitation (Sevruk, 1997) hamper the de-biasing 


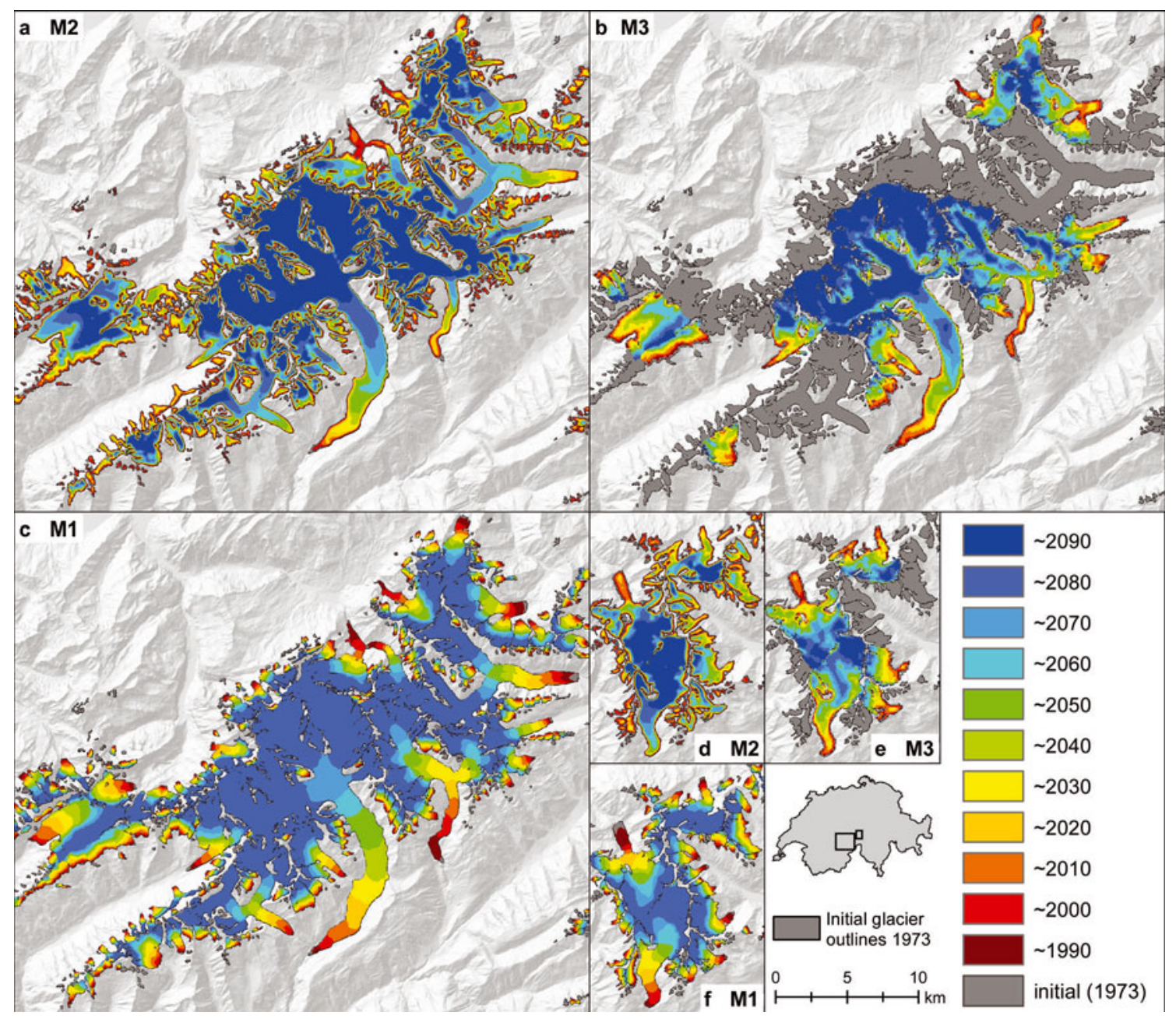

Fig. 4. Visualization of the results for the regions around Aletsch $(a-c)$ and Rhone $(d-f)$ glaciers for all three models (M1: (c) and (f); M2: (a) and (d); M3: (b) and (e)) with their moderate climate scenario, starting with their 1973 extent (i.e. DEM25). The colour steps depict 10 year changes and are the same for all models. The modelling with M3 was restricted to the subsample of 101 glaciers.

procedure and make it impossible to achieve a level of accuracy that would allow the calculation of accurate mass balances for each individual glacier. This issue is reflected in the successful model-calibration to observed melt during the summer period while at the same time winter mass balance strongly disagrees with measurements (Machguth and others, 2009). We have approached these limitations by applying a calibration procedure, where the mass-balance model is driven by the downscaled and de-biased RCM time series for the period 1970-2000 and precipitation is adjusted for each glacier individually to achieve a prescribed cumulative mass balance (Machguth and others, 2012). Choosing an appropriate value for the cumulative mass balance is challenging, as available observations differ: while Zemp and others (2008) report a mean cumulative mass balance of $-13 \mathrm{~m}$ w.e. for nine Alpine glaciers, Huss and others $(2010 \mathrm{~b}, \mathrm{c})$ calculate $-9 \mathrm{~m}$ w.e. from a combined approach of modelling and observations. We prescribe a cumulative mass balance of -11 mw.e., which is midway between the two values. Furthermore, all glaciers were calibrated to the same cumulative mass balance. This simplification had to be introduced because, for most of the 101 selected glaciers, no individual observational records are available. We are confident that the latter simplification only marginally affects the calculated future glacier volumes. Salzmann and others (2012) applied the same model chain and showed that using alternative sets of non-uniform cumulative mass balances in the calibration procedure has a negligible impact on future scenarios. The downscaled, de-biased and calibrated RCM data are subsequently used to run the mass-balance model over the entire scenario period.

\section{RESULTS}

The simulated glacier area loss for all three models is illustrated in Figure 4. For M1 the moderate scenario is displayed, with an ELA shift of $150 \mathrm{~m}$ until the first scenario period and a shift of another $200 \mathrm{~m}$ until the second scenario period. As this model is a two-dimensional simplification of a glacier, it is limited to providing area changes (on the initial unchanged DEM) with the lower ends of the glaciers simply cut off. This leads to glacier geometries with cropped ablation and unchanged accumulation areas. The visual comparison with the moderate $\mathrm{M} 2$ and the $\mathrm{M} 3 \mathrm{E} 7 \mathrm{~m}$ scenario is provided nevertheless.

Models M2 and M3 additionally require the ice-thickness distribution to calculate ice volume change, as a combination of surface lowering and area reduction. The resulting patterns of glacier shrinkage seem to be closer to reality than for $\mathrm{M} 1$, where for some glaciers the shrinkage starts along the edges (where the ice is thin) at the lowest elevations (where thinning is greatest). The visual comparison of M2 

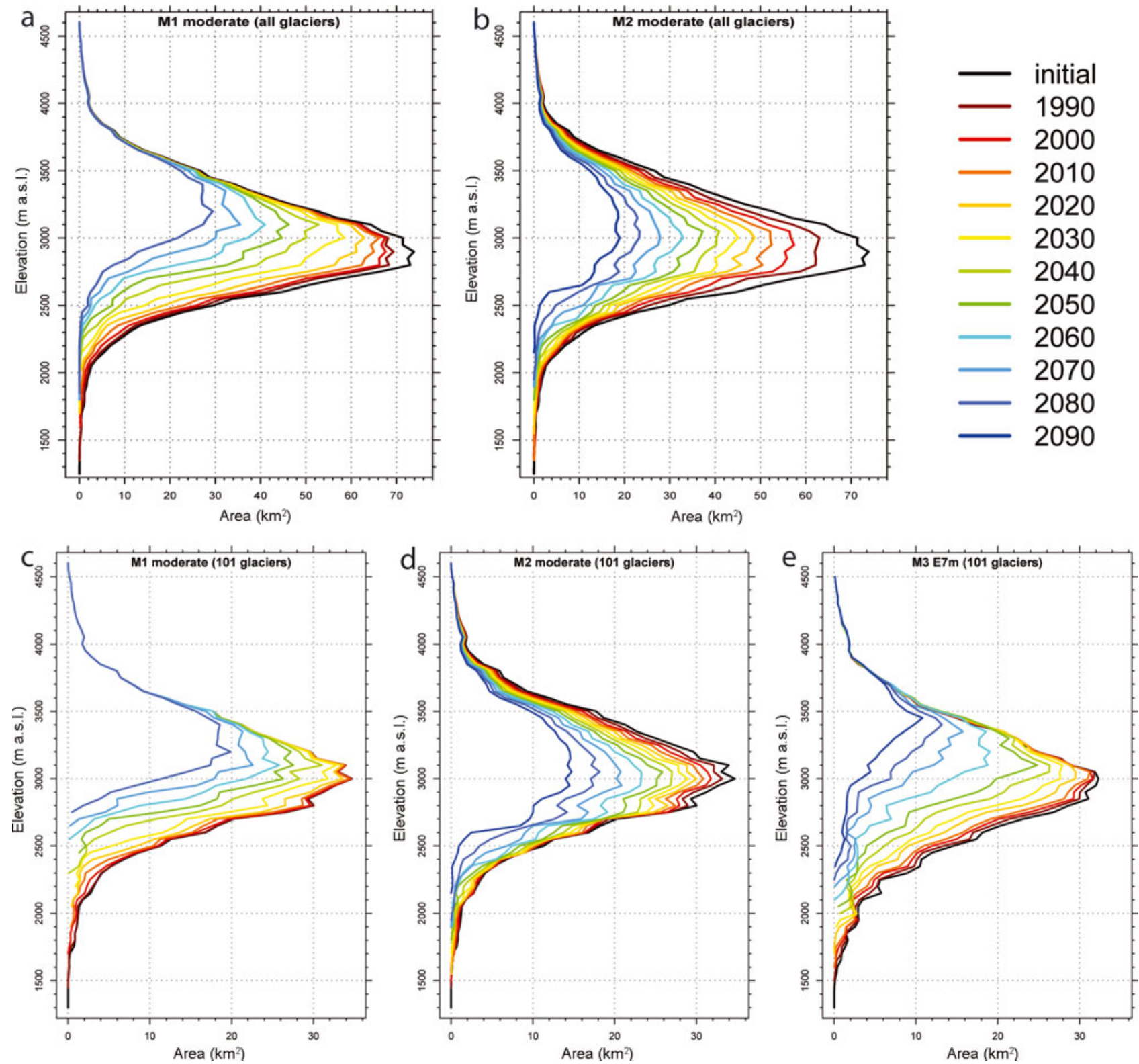

Fig. 5. Change in overall glacier hypsometry in 10 year steps (colour code is the same as in Fig. 4) until 2090 (2080 for M1) for all glaciers $(\mathrm{a}, \mathrm{b})$ and the 101 selected glaciers (c-e), calculated with the moderate temperature scenarios of M1 (a, c) and M2 (b, d) and ensembles scenario E7m from M3 (e).

and $\mathrm{M} 3$ in Figure 4 and the quantitative comparison in Figure $6 \mathrm{~d}$ indicate that the area loss in M3 is slightly faster than for M2.

The evolution of the area/elevation distribution (hypsometry) for 10 year time-steps and the three moderate climate scenarios is depicted in Figure 5. While for model M1 the entire distribution, including the maximum value, is shifted upwards, model M2 shows a constant decrease at all elevations without a trend in the maximum. This is due to the implemented elevation feedback, i.e. large parts of the surface area shift to lower elevations (where melting is higher). Focusing on just the 101 selected glaciers from M3 using the other two models (Fig. 5, lower panels), the trends of the area distribution for $M 1$ and $M 2$ are the same as for the full sample. Interestingly, the hypsometric changes of M3 are rather similar to $\mathrm{M} 1$, but with an overall stronger loss in area at higher elevations and a reduced loss at lower elevations. In contrast to M1 and M2 which work at $25 \mathrm{~m}$ resolution, M3 operates at $100 \mathrm{~m}$ resolution. Therefore, the initial glacier areas in Figure 5c and d and Figure 5e are not exactly the same.

Figure 6a-d show the temporal development of the area loss (and volume loss for M3) during the 21st century for all three models and their different realizations, corresponding to the different applied climate scenarios, the thickness uncertainty (M2) and the full sample vs the 101 selected glaciers (M1, M2). The development of the relative area change along the various model pathways is, to a large extent, similar, but differences are also visible. There is a spread of $\sim 10-20 \%$ around the near future (2035) and of $\sim 30-50 \%$ at the end of the century for the various model realizations in all four plots. Considering the simulations for the sample of the selected 101 glaciers, the general trend for all model realizations is the same: by mid-century the area loss is still moderate, but it then increases sharply until the end of the century, especially with M3 and the hightemperature scenarios of M1. This is also reflected in the glacier hypsometry modelled by M3 (Fig. 5e), which shows a 

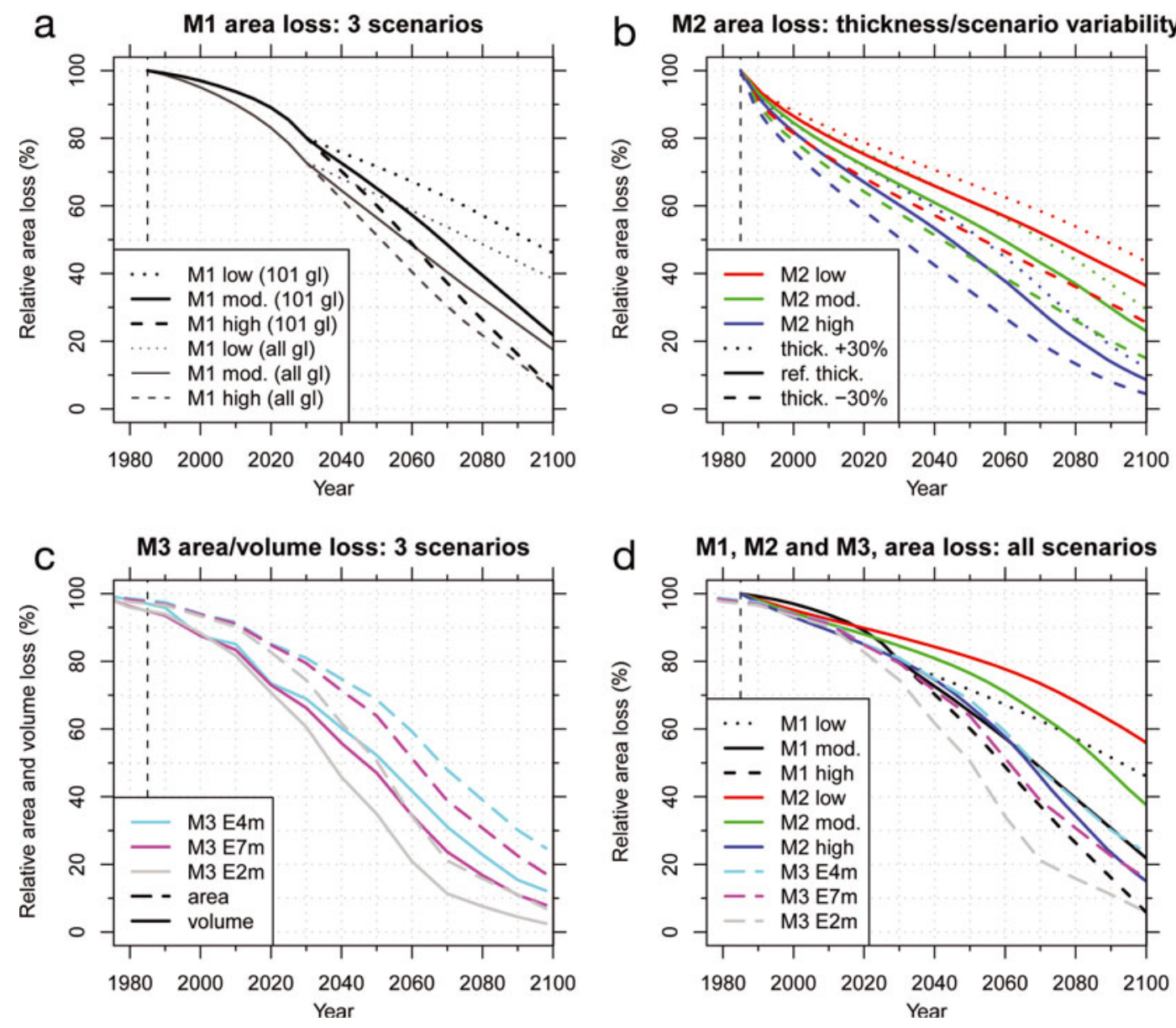

Fig. 6. Development of relative area loss from the model starting point (1985 for M1 and M2; 1970 for M3) until 2100 for all three models and their different realizations (scenarios, thickness, glacier samples). (a) The three retrospective applied scenarios for M1 represented by the grey lines for all glaciers and in black (bold) for the 101 glaciers. (b) The three different temperature trend extrapolations applied in M2 together with the corresponding $\pm 30 \%$ uncertainty due to the ice-thickness modelling for all Swiss glaciers. (c) Area and volume loss for the selected 101 glaciers as modelled with the three climate scenario ensembles used in M3. (d) A comparison based on the sample of the selected 101 glaciers of the climate scenario runs from all three models.

marked increase in hypsometric area loss in the second half of the model simulation.

In Figure 6a the curves for the applied climate scenario realizations for M1 (Section 3.1), with a first ELA shift of $150 \mathrm{~m}$ until the first scenario period and a further ELA shift of 100, 200 and $300 \mathrm{~m}$ after the first scenario period, are shown (for all glaciers and the 101 glaciers) leading to a spread of the modelled glacier area of $40 \%$ at the end of the century (loss of $55-95 \%$ by 2100). There is no large difference between the curves for all glaciers and those for the 101 glaciers.

The $30 \%$ uncertainty in the glacier thickness (Fig. 6b) results in a spread of not more than $20 \%$, considering area loss as modelled with M2 for the three climate scenarios. The spread of the lines reproducing area loss according to the three different scenarios is much larger ( $\sim 40 \%$ around the second scenario period), whereby the high-temperature scenario $\left(+5.75^{\circ} \mathrm{C}\right.$ temperature increase by 2100$)$ results in an almost complete loss of glaciers ( 90\%). The uncertainty in ice thickness $( \pm 30 \%)$ has a nonlinear impact on glacier retreat. With $30 \%$ thinner ice the extent of the reference thickness is reached 20 years earlier, while $30 \%$ thicker ice gives only 10 additional years before this extent is reached. Thus, differences in ice-thickness estimations directly impact the timescales of the scenarios, but might have a smaller effect on the remaining ice in 2100 than that resulting from the uncertainties in temperature change (Fig. $6 b$ and d).

In Figure 6c the evolution of area and volume for the selected 101 glaciers as modelled with three scenario ensembles and with M3 is shown. The behaviour of the curves is rather similar, differing only in the speed of area loss, resulting in a spread of $\sim 20 \%$ at the second scenario period.

For the comparison in Figure $6 \mathrm{~d}$, all scenario runs for all three models for the 101 selected glaciers are displayed. It shows that the uncertainties introduced by different realizations of climate change are very similar during the first scenario period and rather large in the second scenario period. Thus, model results increasingly deviate when going into the future. The moderate scenarios of the three models (M1 mod., M2 mod. and M3 E7m) result in a total loss of glacier area of $\sim 60-80 \%$ by around the year 2100 . In terms of area loss, the scenarios M1 mod., M2 high, M3 E4m and M3 E7m are close together, i.e. they do not differ by more than $15 \%$. The area loss modelled by scenarios M1 low, M2 mod. and, in particular, M2 low is rather slow compared to the other scenarios and can be seen as a lower boundary.

The variable curvature of the lines reveals interesting details about the speed of glacier shrinkage at various phases of the recession, largely depending on the remaining area covered by thick ice. A key aspect is that all curves will 
Table 1. Comparison of area and volume loss and cumulative mass budgets for all scenarios of $M 1, M 2$ and $M 3$ from their model start until the validation year 2000, together with the derived area loss obtained by comparing the two relevant Swiss Glacier Inventories (SGI) from 1973 and 2000. Results are tabulated for all Swiss glaciers and for the subset of 101 glaciers

\begin{tabular}{|c|c|c|c|c|c|c|}
\hline & \multicolumn{2}{|c|}{ Area } & \multicolumn{2}{|c|}{ Volume } & \multirow{2}{*}{$\begin{array}{l}\text { Cumulative mass budget } \\
\text { m w.e. }\end{array}$} & \multirow[t]{2}{*}{ Time period } \\
\hline & $\%$ & $\mathrm{~km}^{2}$ & $\%$ & $\mathrm{~km}^{3}$ & & \\
\hline M1 all & -5 & -61 & - & - & - & 1985-2000 \\
\hline M1 101 & -3 & -19 & - & - & - & 1985-2000 \\
\hline M2 low all & -13 & -176 & -8 & -6.4 & -5.6 & 1985-2000 \\
\hline M2 low 101 & -5 & -31 & -6 & -3.1 & -5.1 & 1985-2000 \\
\hline M2 mod. all & -15 & -202 & -10 & -7.6 & -7.4 & 1985-2000 \\
\hline M2 mod. 101 & -6 & -36 & -7 & -3.7 & -6.0 & 1985-2000 \\
\hline M2 high all & -19 & -249 & -13 & -9.9 & -10.1 & 1985-2000 \\
\hline M2 high 101 & -7 & -47 & -9 & -5.0 & -8.6 & 1985-2000 \\
\hline M3 E4m 101 & -6 & -38 & -13 & -6.8 & -11.0 & 1970-2000 \\
\hline M3 E7m 101 & -6 & -39 & -12 & -6.7 & -11.0 & 1970-2000 \\
\hline M3 E2m 101 & -7 & -42 & -12 & -6.3 & -11.0 & 1970-2000 \\
\hline SGI all & -20 & -268 & - & - & $-11^{*}$ & 1973-2000 \\
\hline SGI 101 & -9 & -56 & - & - & - & 1973-2000 \\
\hline
\end{tabular}

*The indicated cumulative mass budgets for 'SGI all' refers to the DEM differencing of Paul and Haeberli (2008) and the ice-thickness modelling of Linsbauer and others (2012).

finally approach 0 , i.e. glaciers are unable to stabilize their extent for the given scenarios of climate change. This behaviour is also visible in the hypsometric changes in Figure $5 b$, where the area loss (all glaciers) is relatively large between the initial and the first step, whereas in Figure $5 d$ there is not much difference between these two curves.

In contrast to $M 1$ and $M 2$, which have a fixed starting point in 1985, the model start of M3 is 1970 . This is done to maximize the length of the calibration period. For the model comparison the earlier starting point of M3 is of negligible importance, as the climate was approximately stable and, according to $\mathrm{M} 3$, only $2.5 \%\left(15 \mathrm{~km}^{2}\right)$ of the area and $5 \%$ $\left(2.8 \mathrm{~km}^{3}\right)$ of the initial volume were lost between 1970 and 1985 .

\section{VALIDATION}

For M3 (and all three ensemble scenarios) the cumulative mass balance for the time period 1970-2000 is calibrated to an overall mass loss of $-11 \mathrm{~m}$ w.e., the mean calculated from the observed cumulative mass budget of Zemp and others (2008) ( $-13 \mathrm{~m}$ w.e.) and Huss and others (2010b,c) ( $-9 \mathrm{~m}$ w.e.) (Salzmann and others, 2012). Within this calibration period, a model validation for M1, M2 and M3 would be possible, as corresponding and consistent glacier outlines for nearly all Swiss glaciers exist for 1973 and 2000 (SGI2000; Paul, 2007). In Table 1 the area (and where available the volume) of all model scenarios and the glacier inventories is displayed to allow comparison in a quantitative manner. The observed area loss is 20\% for all glaciers and 9\% for the 101 glaciers. The M3 scenarios and the moderate and high M2 scenarios do not differ by more than $5 \%$ from these values. The cumulative mass budgets for the M3 scenarios are calibrated, but the value obtained for the high M2 scenario for all glaciers corresponds rather well to the observations (Paul and Haeberli, 2008). Cumulative mass budget for the moderate M2 scenario is within the range of values of Huss and others $(2010 \mathrm{~b}, \mathrm{c})$. Area (and volume) losses for M1 and the low M2 scenario are probably too low. This is expected for $M 1$, where only the lowermost parts of the glaciers were removed, according to an $\mathrm{AAR}_{0}$ of $60 \%$. As many of the lower parts of the larger glaciers in 1973 ended in narrow tongues, only minor parts of the area are deleted.

In Figure 7 a comparison of observed and modelled glacier extents for the year 2000 is shown for the glaciers in the Bernina region. It has to be kept in mind that $\mathrm{M} 1$ and $\mathrm{M} 2$ are designed to model glacier evolution on a regional scale, rather than individual glaciers, and that only three time-steps are applied until 2000. As can be seen, the changes in the observed glacier extents (1973-2000) for the large glaciers occur at the snout and along the edges. Some glaciers show a distinct retreat of the tongue from 1973 to 2000, but in general all glaciers lost area all over their margins due to the implemented surface lowering.

For the glaciers depicted in Figure 7 , both $M 2$ and $M 3$ reproduce well the observed inward shift of glacier boundaries due to surface lowering. The agreement between observed and modelled terminus positions of Tremoggia, Tschierva and Morteratsch glaciers is good, while the modelled retreat for Palü and, especially, Roseg glaciers is too small (Fig. 7). Generally, the area and in particular the volume loss as modelled with M3 is larger than with M2, as mentioned above (Figs 4-6). This is also illustrated in the inset map of Figure 7 . It shows the tongue of Tschierva glacier with outlines for the year 2000 as modelled by all models (and scenarios). M1 shows the typical pattern resulting from cutting off the lowermost part of the tongue, with a retreat of about $200 \mathrm{~m}$ compared to the mapped glacier outline, while the other two models achieve a glacier outline similar to the mapped tongue position.

\section{DISCUSSION}

\subsection{Simplifications and uncertainties}

Concerning the glacier change models and the climate change scenarios, several simplifications and uncertainties need to be discussed. Although there is general agreement concerning temperature development in the climate models used, changes in precipitation are highly uncertain and do not show a significant trend (e.g. Bosshard and others, 2011). They are only considered in M3 and have been neglected for 


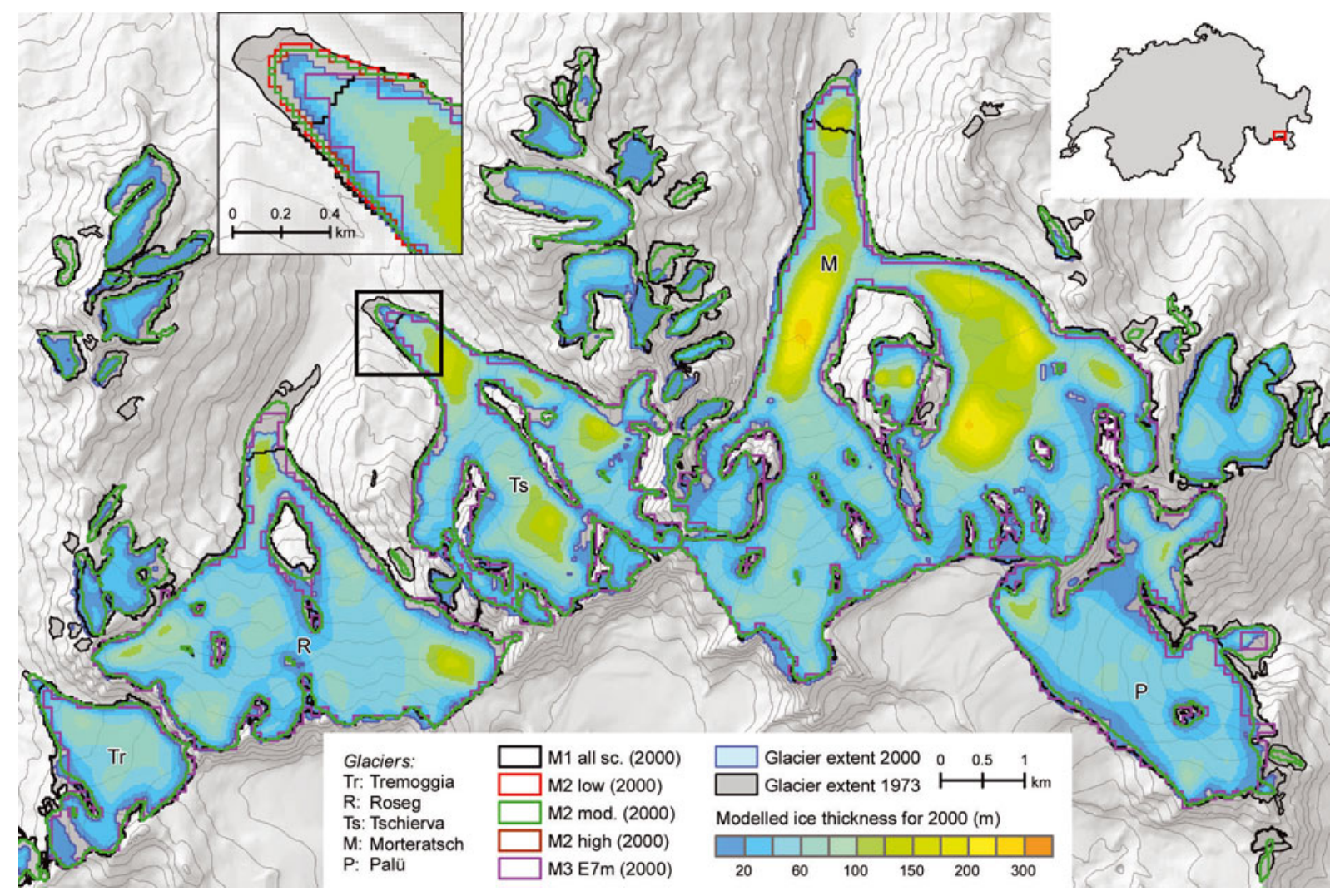

Fig. 7. The extents of glaciers in the Bernina region according to the inventories from 1973 and 2000 and the modelled ice thickness for the year 2000 according to Linsbauer and others (2012), compared to the modelled area evolution with the moderate scenarios of M1, M2 and M3 for the time-step corresponding to the year 2000. The inset shows the Tschierva glacier snout with all the glacier margins according to all model scenarios.

$\mathrm{M} 1$ and $\mathrm{M} 2$. A further simplification in M1 is that all glaciers have the same temperature sensitivity $(150 \mathrm{~m}$ ELA rise per $\left.{ }^{\circ} \mathrm{C}\right)$, response time (50 years) and $\mathrm{AAR}_{0}(60 \%)$ (Section 3.1). Apart from the response time, these are typical mean values that certainly differ from glacier to glacier. Response time is somewhat biased towards larger glaciers, but this is required, as they are the main contributors to the overall area and volume change and should thus not shrink too fast. The parameterization of $\mathrm{M} 2$ is based on three linear extrapolations of an observed trend (elevation change in response to a $1^{\circ} \mathrm{C}$ increase), and all glaciers follow the same elevationdependent thickness loss, using an empirical generalization rather than a regression. The three assumed time periods for glacier surface adjustment constitute a best guess to cover three scenarios for M2. The underlying climate scenarios of M3 are based on RCM simulations (ensemble means) and are thus beyond a simple linear extrapolation. M3 is also restricted to a subsample of selected glaciers that adhere to specific criteria (Section 3.3) to be suitable for the applied mass-balance model. Models M2 and M3 are based on a modelled ice-thickness distribution with an estimated uncertainty of about $\pm 30 \%$, that directly impacts on the timescale of the modelled glacier retreat.

We have not explicitly assessed the impact of all the simplifications mentioned above on glacier evolution. In general, many of the effects will average out when large samples are considered, as deviations from the mean values used are probably normally distributed (apart from the response-time bias). The hypothesis is not explicitly tested, but, for natural systems and large samples of independent data, deviations from a mean should be normally distributed.
For individual glaciers the differences between the development modelled here and a model that considers glacier characteristics more explicitly may be large. However, for regional-scale assessment these differences are expected to contribute mainly to the variability rather than the trend, and both are governed by the implemented climate scenario.

All model approaches investigated here have advantages and disadvantages, and were designed for specific research questions. All three models operate on a regional scale, but M3 is rather glacier-specific. As a governing principle, a balance between computational effort and the required level of detail in the results has to be found.

\subsection{Possibilities and limitations of model applications}

For a sound model intercomparison, the models can only be compared against observed changes in the past. As the model starting point is 1985 for M1 and M2 and 1970 for M3, there is only a short time period available for a comparison. This comparison might not really be seen as a validation, as none of the models are expected to provide useful results over this timescale. However, for the year 2000, modelled glacier extents fit the mapped ones rather well. As the modelled future changes are much larger than the changes observed over this 15 year period, the significance of this comparison is limited.

The modelled area losses (Fig. 6) clearly reflect the temperature trends of the applied climate scenarios (Fig. 2). The three moderate scenarios that prescribe a $2^{\circ} \mathrm{C}$ or $4{ }^{\circ} \mathrm{C}$ temperature increase for the two scenario periods centred around 2035 and 2085 show a comparable area loss over time (with a maximal spread of $\sim 20 \%$ ). The spread in area 
loss of $\sim 50 \%$ by 2100 is given by the low-temperature scenario of $\mathrm{M} 2$ (upper boundary) and the E2m scenario of M3 (lower boundary).

M1 and M2 are highly simplified models, but provide glacier change scenarios for large glacier samples at a regional scale with a small computational effort. This is in contrast to M3, that better considers characteristics of individual glaciers. Though the simplifications in M1 and M2 are substantial, they might be considered as being compliant with the uncertainties of the RCM scenarios, i.e. the variability in area change introduced by the simplifications is of the same order of magnitude as that resulting from the unknown future climate. According to the results of this comparison, the latter is somewhat larger. For studies seeking to establish future trends in the glacier cover of entire mountain ranges (e.g. the Swiss Alps), M1 and M2 are fast approaches providing results similar to the more detailed modelling of M3. As both models apply average parameter sets to all Swiss glaciers, the results are valid on the sample as a whole. We also found agreement with results from completely different studies (Jouvet and others, 2009, 2011; Huss and others, 2010a; Huss, 2012), which is not surprising as the strong future temperature increase dominates the response. The simple approach of $M 1$ was designed to provide adjusted glacier areas as an input for hydrological models operating at a regional scale (e.g. Viviroli and others, 2009; Köplin and others, 2012). This study has shown that area loss is fastest in M1, which can be seen as a lower-bound timescale for the expected terminus retreat. For the hydrological model that generates additional runoff solely from the change in glacier area, the stronger area change in M1 might be well suited to mimic the expected future increase in runoff due to downwasting, a process that is not included in $\mathrm{M} 1$ but important in reality.

Although all three models are based on equivalent climate scenarios and RCM runs, the coupling to the climate model output is rather different: retrospective with $M 1$; based on trend extrapolation with $\mathrm{M} 2$; and directly driven by RCM grids in M3. The modelled future development in glacier extent with the moderate scenarios can already be seen as lower-bound estimates, as the current temperature increase is already stronger and modelled mean annual thickness loss from 2000 to 2010 (with M2 mod. and M3 E7m; Fig. 8) is only $0.4 \mathrm{~m} \mathrm{a}^{-1}$ according to the models, instead of the observed $0.8 \mathrm{~m} \mathrm{a}^{-1}$ (Zemp and others, 2009). The decrease in mean annual thickness change in the last part of the modelling period for all scenarios in M3 (Fig. 8) may be related to the direct coupling with RCM data (allowing for positive and negative mass balances) and a possible future adjustment of the remaining small glaciers at high elevation.

Finally, it has to be considered that several feedbacks are not incorporated in any of the models, including the change of albedo (Oerlemans and others, 2009), development of new lakes (Frey and others, 2010), increasing debris cover (Jouvet and others, 2011) and changes in glacier thermal state (Vincent and others, 2007; Hoelzle and others, 2011). The local and general influence of these processes is difficult to assess because they partly act in opposite directions.

\section{CONCLUSION}

The three compared approaches for calculating future glacier evolution use robust (based on simple physical laws or observations) but simplified parameterizations that are

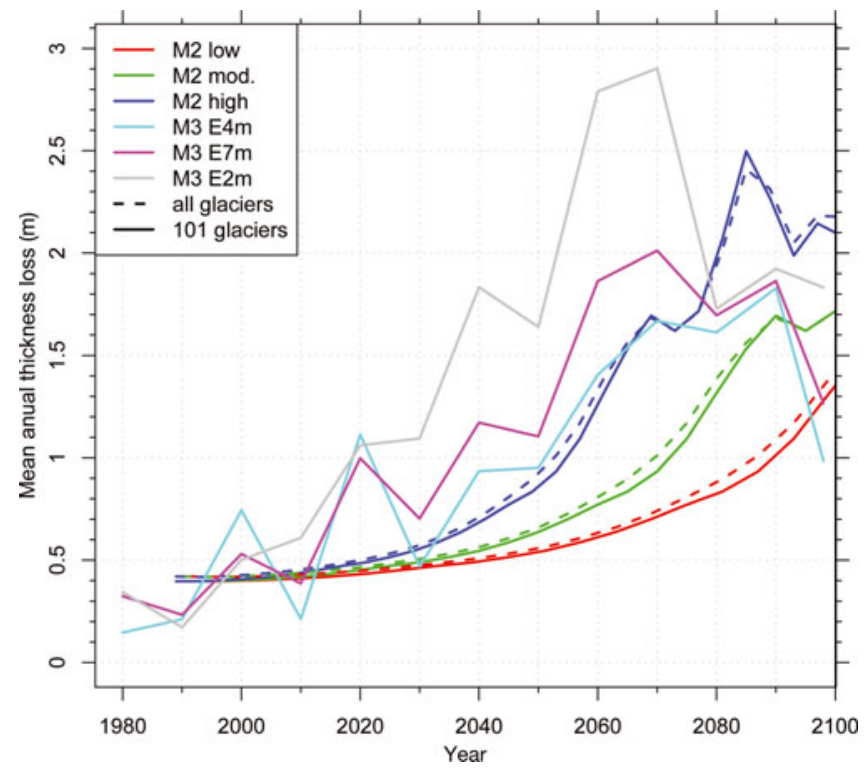

Fig. 8. Mean annual thickness loss over time, as derived from the three scenarios of $\mathrm{M} 2$ and the three ensemble means of M3.

applicable to large glacier samples. Two of the models are implemented in a GIS processing environment and enable glacier change scenarios to be simulated at a regional scale with small computational costs. From the comparison of the three models we conclude the following:

The moderate scenarios of the three models give a relative area loss of $60-80 \%$ by 2100 compared to the glacier extent in 1985; in reality, glacier vanishing could be even more rapid.

Due to the simplifications induced by the parameterization schemes, uncertainties are large at a local scale (individual glaciers), but are likely to average out at the regional scale (Swiss Alps) and over extended time periods (decades to a century).

The overall trends of the modelled future glacier evolution - a strong to almost complete loss of glaciers by the end of the 21 st century - are therefore clear and robust as air temperatures are expected to increase further.

The variability in the climate scenarios leads to a maximum spread of $\sim 40 \%$ in the remaining area by 2100 (relative loss of $55-95 \%$ ).

The uncertainty in estimations of present-day ice thickness (about $\pm 30 \%$ ) has a smaller but still considerable effect and impacts directly and non-symmetrically on the timescale of the modelled future glacier development.

The probably strong impact of unconsidered feedback processes (albedo change, lake formation, subglacial ablation, debris cover, etc.) needs further investigation.

All three models have advantages and disadvantages in their application. Which model to choose for a specific application depends on data availability and the level of detail required in the output. $\mathrm{M} 1$ and $\mathrm{M} 2$ have proven to provide fast and robust first-order estimates for glacier retreat, dominated by temperature increase. They might be less suitable when changes in precipitation have to be considered as well, but here the uncertainties are even larger. 


\section{ACKNOWLEDGEMENTS}

This study was funded by BAFU (Swiss Federal Office for the Environment) and FMV (Forces Motrices Valaisannes) as part of two research projects CCHydro and 'Climate change and hydropower'. We acknowledge MeteoSwiss for providing the meteorological observations, and swisstopo for the DEM. The delta change scenario data were distributed by the Center for Climate Systems Modeling (C2SM). The data were derived from regional climate simulations of the European Union FP6 Integrated Project ENSEMBLES (contract No. 505539). The dataset was prepared by T. Bosshard at ETH Zürich, partly funded by swisselectric/Swiss Federal Office of Energy (BFE) and CCHydro/BAFU. We thank M. Hoelzle for helpful remarks. The constructive comments of the editor, V. Radić, and two anonymous reviewers helped to improve the manuscript considerably.

\section{REFERENCES}

Bahr DB, Dyurgerov M and Meier MF (2009) Sea-level rise from glaciers and ice caps: a lower bound. Geophys. Res. Lett., 36(3), L03501 (doi: 10.1029/2008GL036309)

Begert M, Schlegel T and Kirchhofer W (2005) Homogeneous temperature and precipitation series of Switzerland from 1864 to 2000. Int. J. Climatol., 25(1), 65-80 (doi: 10.1002/joc.1118)

Bosshard T, Kotlarski S, Ewen T and Schär C (2011) Spectral representation of the annual cycle in the climate change signal. Hydrol. Earth Syst. Sci. Discuss., 8(1), 1161-1192 (doi: 10.5194/ hessd-8-1161-2011)

Condom TH, Coudrain A, Sicart JE and Théry S (2007) Computation of the space and time evolution of equilibrium-line altitudes on Andean glaciers $\left(10^{\circ} \mathrm{N}-55^{\circ} \mathrm{S}\right)$. Global Planet. Change, 59(1-4), 189-202 (doi: 10.1016/j.globplacha.2006.11.021)

Farinotti D, Huss M, Bauder A and Funk M (2009) An estimate of the glacier ice volume in the Swiss Alps. Global Planet. Change, 68(3), 225-231 (doi: 10.1016/j.gloplacha.2009.05.004)

Farinotti D, Usselmann S, Huss M, Bauder A and Funk M (2012) Runoff evolution in the Swiss Alps: projections for selected highalpine catchments based on ENSEMBLES scenarios. Hydrol. Process., 26(13), 1909-1924 (doi: 10.1002/hyp.8276)

Fischer A, Olefs M and Abermann J (2011) Glaciers, snow and ski tourism in Austria's changing climate. Ann. Glaciol., 52(58), 8996 (doi: 10.3189/172756411797252338)

Frey H, Haeberli W, Linsbauer A, Huggel C and Paul F (2010) A multi-level strategy for anticipating future glacier lake formation and associated hazard potentials. Natur. Hazards Earth Syst. Sci. (NHESS), 10(2), 339-352

Giesen RH and Oerlemans J (2012) Global application of a surface mass balance model using gridded climate data. Cryos. Discuss., 6(2), 1445-1490 (doi: 10.5194/tcd-6-1445-2012)

Greuell W, Knap WH and Smeets PC (1997) Elevational changes in meteorological variables along a mid-latitude glacier during summer. J. Geophys. Res., 102(D22), 25941-25954 (doi: 10.1029/97JD02083)

Guo Z, Dirmeyer PA, Gao X and Zhao M (2007) Improving the quality of simulated soil moisture with a multi-model ensemble approach. Q. J. R. Meteorol. Soc., 133(624), 731-747 (doi: 10.1002/qj.48)

Haeberli W and Hoelzle M (1995) Application of inventory data for estimating characteristics of and regional climate-change effects on mountain glaciers: a pilot study with the European Alps. Ann. Glaciol., 21 206-212

Haeberli W, Clague JJ, Huggel C and Kääb A (2010) Hazards from lakes in high-mountain glacier and permafrost regions: climate change effects and process interactions. In Úbeda X, Vericat D and Batalla R eds. Avances de la geomorfología en Espãna, 20082010. Societat Espanyola de Geomorfologia, Barcelona, 439-446
Hoelzle M, Paul F, Gruber S and Frauenfelder R (2005) Glaciers and permafrost in mountain areas: different modeling approaches. In Global change impacts in mountain biosphere reserves. UNESCO, Paris, 28-39 http://unesdoc.unesco.org/images/0014/ 001424/142482E.pdf

Hoelzle M, Darms G, Lüthi MP and Suter S (2011) Evidence of accelerated englacial warming in the Monte Rosa area, Switzerland/Italy. Cryosphere, 5(1), 231-243 (doi: 10.5194/tc5-231-2011)

Huss M (2011) Present and future contribution of glacier storage change to runoff from macroscale drainage basins in Europe. Water Resour. Res., 47(W7), W07511 (doi: 10.1029/ 2010WR010299)

Huss M (2012) Extrapolating glacier mass balance to the mountainrange scale: the European Alps 1900-2100. Cryosphere, 6(4), 713-727 (doi: 10.5194/tc-6-713-2012)

Huss M, Farinotti D, Bauder A and Funk M (2008) Modelling runoff from highly glacierized alpine drainage basins in a changing climate. Hydrol. Process., 22(19), 3888-3902 (doi: 10.1002/ hyp.7055)

Huss M, Jouvet G, Farinotti D and Bauder A (2010a) Future highmountain hydrology: a new parameterization of glacier retreat. Hydrol. Earth Syst. Sci., 14(5), 815-829 (doi: 10.5194/hess-14815-2010)

Huss M, Hock R, Bauder A and Funk M (2010b) 100-year mass changes in the Swiss Alps linked to the Atlantic Multidecadal Oscillation. Geophys. Res. Lett., 37(10), L10501 (doi: 10.1029/ 2010GL042616)

Huss M, Usselmann S, Farinotti D and Bauder A (2010c) Glacier mass balance in the south-eastern Swiss Alps since 1900 and perspectives for the future. Erdkunde, 64(2), 119-140 (doi: 10.3112/erdkunde.2010.02.02)

Jouvet G, Huss M, Blatter H, Picasso M and Rappaz J (2009) Numerical simulation of Rhonegletscher from 1874 to 2100. J. Comput. Phys., 228(17), 6426-6439 (doi: 10.1016/j.jcp. 2009.05.033)

Jouvet G, Huss M, Funk M and Blatter H (2011) Modelling the retreat of Grosser Aletschgletscher, Switzerland, in a changing climate. J. Glaciol., 57(206), 1033-1045 (doi: 10.3189/ 002214311798843359)

Köplin N, Schädler B, Viviroli D and Weingartner R (2012) The importance of glacier and forest change in hydrological climate-impact studies. Hydrol. Earth Syst. Sci. Discuss., 9(5), 5983-6021 (doi: 10.5194/hessd-9-5983-2012)

Kuhn M (1981) Climate and glaciers. IAHS Publ. 131 (Symposium at Canberra 1979 - Sea Level, Ice and Climatic Change), 3-20

Künzler M, Huggel C, Linsbauer A and Haeberli W (2010) Emerging risks related to new lakes in deglaciating areas of the Alps. In Malet JP, Glade Tand Casagli N eds. Mountain risks: bringing science to society. Proceedings of the 'Mountain Risk' International Conference, 24-26 November, 2010, Firenze, Italy. Centre Européen sur les Risques Géomorphologiques, Strasbourg, 453-458

Le Meur E, Gerbaux M, Schäfer M and Vincent C (2007) Disappearance of an Alpine glacier over the 21st century simulated from modeling its future surface mass balance. Earth Planet. Sci. Lett., 261(3-4), 367-374 (doi: 10.1016/ j.epsl.2007.07.022)

Li H, Ng F, Li Z, Qin D and Cheng G (2012) An extended 'perfectplasticity' method for estimating ice thickness along the flow line of mountain glaciers. J. Geophys. Res., 117(F1), F01020 (doi: 10.1029/2011JF002104)

Lie O, Dahl SO and Nesje A (2003) Theoretical equilibrium-line altitudes and glacier buildup sensitivity in southern Norway based on meteorological data in a geographical information system. Holocene, 13(3), 373-380

Linsbauer A, Paul F and Haeberli W (2012) Modeling glacier thickness distribution and bed topography over entire mountain ranges with GlabTop: application of a fast and robust approach. J. Geophys. Res., 117(F3), F03007 (doi: 10.1029/2011JF002313) 
Machguth H, Paul F, Kotlarski S and Hoelzle M (2009) Calculating distributed glacier mass balance for the Swiss Alps from regional climate model output: a methodical description and interpretation of the results. J. Geophys. Res., 114(D19), D19106 (doi: 10.1029/2009JD011775)

Machguth H, Haeberli W and Paul F (2012) Mass balance parameters derived from a synthetic network of mass-balance glaciers. J. Glaciol., 58(211), 965-979 (doi: 10.3189/ 2012JoG11J223)

Maisch M, Wipf A, Denneler B, Battaglia J and Benz C (2000) Die Gletscher der Schweizer Alpen. Gletscherhochstand 1850, Aktuelle Vergletscherung, Gletscherschwund-Szenarien. (Schlussbericht NFP 31) vdf Hochschulverlag AG ETH, Zürich

Marzeion B, Hofer M, Jarosch AH, Kaser G and Mölg T (2012) A minimal model for reconstructing interannual mass balance variability of glaciers in the European Alps. Cryosphere, 6(1), 71-84 (doi: 10.5194/tc-6-71-2012)

Mauser W and Bach H (2009) PROMET - Large scale distributed hydrological modelling to study the impact of climate change on the water flows of mountain watersheds. J. Hydrol., 376(3-4), 362-377 (doi: 10.1016/j.jhydrol.2009.07.046)

Moore RD and 7 others (2009) Glacier change in western North America: influences on hydrology, geomorphic hazards and water quality. Hydrol. Process., 23(1), 42-61 (doi: 10.1002/ hyp.7162)

Müller F, Caflisch T and Müller G (1976) Firn und Eis der Schweizer Alpen: Gletscherinventar. (Geographisches Institut Publ. 57) Eidgenössische Technische Hochschule, Zürich

Oerlemans J (2001) Glaciers and climate change. AA Balkema, Lisse

Oerlemans J, Giesen RH and Van den Broeke MR (2009) Retreating alpine glaciers: increased melt rates due to accumulation of dust (Vadret da Morterastch, Switzerland). J. Glaciol., 55(192), 729-736 (doi: 10.3189/002214309789470969)

Paterson WSB (1994) The physics of glaciers, 3rd edn. Elsevier, Oxford

Paul F (2007) The new Swiss glacier inventory 2000 - application of remote sensing and GIS. Schr. Phys. Geogr. 52

Paul F and Haeberli W (2008) Spatial variability of glacier elevation changes in the Swiss Alps obtained from two digital elevation models. Geophys. Res. Lett., 35(21), L21502 (doi: 10.1029/ 2008GL034718)

Paul F and Linsbauer A (2012) Modeling of glacier bed topography from glacier outlines, central branch lines, and a DEM. Int. J. Geogr. Inf. Sci., 26(7), 1173-1190 (doi: 10.1080/ 13658816.2011.627859)

Paul F, Kääb A, Maisch M, Kellenberger T and Haeberli W (2004) Rapid disintegration of Alpine glaciers observed with satellite data. Geophys. Res. Lett., 31(21), L21402 (doi: 10.1029/ 2004GL020816)

Paul F, Maisch M, Rothenbühler C, Hoelzle M and Haeberli W (2007) Calculation and visualisation of future glacier extent in the Swiss Alps by means of hypsographic modelling. Global Planet. Change, 55(4), 343-357 (doi: 10.1016/j.gloplacha. 2006.08.003)

Radić V and Hock R (2011) Regionally differentiated contribution of mountain glaciers and ice caps to future sea-level rise. Nature Geosci., 4(2), 91-94 (doi: 10.1038/ngeo1052)

Raper SCB and Braithwaite RJ (2005) The potential for sea level rise: new estimates from glacier and ice cap area and volume distributions. Geophys. Res. Lett., 32(5), L05502 (doi: 10.1029/ 2004GL021981)

Raper SCB, Brown O and Braithwaite RJ (2000) A geometric glacier model for sea-level change calculations. J. Glaciol., 46(154), 357-368 (doi: 10.3189/172756500781833034)

Raymond CF, Neumann TA, Rignot E, Echelmeyer K, Rivera A and Casassa G (2005) Retreat of Glaciar Tyndall, Patagonia, over the last half-century. J. Glaciol., 51(173), 239-247 (doi: 10.3189/ 172756505781829476)

Rebetez M and Reinhard M (2008) Monthly air temperature trends in Switzerland 1901-2000 and 1975-2004. Theor. Appl. Climatol., 91(1-4), 27-34 (doi: 10.1007/s00704007-0296-2)

Rickenbacher M (1998) Die digitale Modellierung des Hochgebirges im DHM25 des Bundessamtes für Landestopographie. Wien. Schrift. Geogr. Kartogr., 11, 49-55

Salzmann N, Machguth H and Linsbauer A (2012) The Swiss Alpine glaciers' response to the global ' $2{ }^{\circ} \mathrm{C}$ air temperature target'. Environ. Res. Lett., 7(4), 044001 (doi: 10.1088/1748-9326/7/4/ 044001)

Schaefli B, Hingray B and Musy A (2007) Climate change and hydropower production in the Swiss Alps: quantification of potential impacts and related modelling uncertainties. Hydrol. Earth Syst. Sci., 11(3), 1191-1205

Schwarb M, Daly C, Frei C and Schär C (2001) Mean annual precipitation throughout the European Alps, 1971-1990. In Hydrological atlas of Switzerland. National Hydrologic Service, Bern, plates 2.6-2.7

Sevruk B (1997) Regional dependency of precipitation-altitude relationship in the Swiss Alps. Climatic Change, 36(3-4), 355-369 (doi: 10.1023/A:1005302626066)

Solomon S and 7 others eds. (2007) Climate change 2007: the physical science basis. Contribution of Working Group I to the Fourth Assessment Report of the Intergovernmental Panel on Climate Change. Cambridge University Press, Cambridge

swisstopo (2005) DHM25, das digitale Höhenmodel der Schweiz. Federal Office of Topography, swisstopo, Wabern

Terrier S, Jordan F, Schleiss A, Haeberli W, Huggel C and Künzler M (2011) Optimized and adapted hydropower management considering glacier shrinkage scenarios in the Swiss Alps. In Schleiss A and Boes RM eds. Proceedings of the International Symposium on Dams and Reservoirs under Changing Challenges. 79th Annual Meeting of ICOLD, Swiss Committee on Dams, Lucerne, Switzerland. Taylor and Francis, London, 497-508

Van der Linden P and Mitchell JFB (2009) ENSEMBLES: climate change and its impacts: summary of research and results from the ENSEMBLES project. Met Office Hadley Centre, Exeter

Vincent C, Le Meur E, Six D, Possenti P, Lefebvre E and Funk M (2007) Climate warming revealed by englacial temperatures at Col du Dôme (4250 m, Mont Blanc area). Geophys. Res. Lett., 34(16), L16502 (doi: 10.1029/2007GL029933)

Viviroli D, Zappa M, Gurtz J and Weingartner R (2009) An introduction to the hydrological modelling system PREVAH and its pre- and post-processing-tools. Environ. Model. Softw., 24(10), 1209-1222 (doi: 10.1016/j.envsoft.2009.04.001)

World Glacier Monitoring Service (WGMS) (2011) Glacier Mass Balance Bulletin No. 11 (2008-2009), eds. Zemp M, Nussbaumer SU, Gärtner-Roer I, Hoelzle M, Paul F and Haeberli W. ICSU(WDS)/IUGG(IACS)/UNEP/UNESCO/WMO, World Glacier Monitoring Service, Zürich

Zemp M, Haeberli W, Hoelzle M and Paul F (2006) Alpine glaciers to disappear within decades? Geophys. Res. Lett., 33(13), L13504 (doi: 10.1029/2006GL026319)

Zemp M, Paul F, Hoelzle M and Haeberli W (2008) Glacier fluctuations in the European Alps, 1850-2000: an overview and a spatiotemporal analysis of available data. In Orlove B, Wiegandt E and Luckman BH eds. Darkening peaks: glacier retreat, science, and society. University of California Press, Berkeley, CA. 152-167

Zemp M, Hoelzle M and Haeberli W (2009) Six decades of glacier mass-balance observations: a review of the worldwide monitoring network. Ann. Glaciol., 50, 101-111 (doi: 10.3189/ 172756409787769591) 